\title{
HÉRNIA LOMBAR ENCARCERADA COMPLICADA COM OBSTRUÇÃO INTESTINAL E PERFURAÇÃO DE CECO
}

\author{
INCARCERATED LUMBAR HERNIA ASSOCIATED TO INTESTINAL \\ OBSTRUCTION AND CECAL PERFURATION
}

\author{
Sinthia Maria Benigno Puttini ${ }^{1}$ \\ André Luiz Vianna, TCBC-DF ${ }^{2}$ \\ Luiz Guilherme Reys, TCBC-DF ${ }^{3}$
}

\section{INTRODUÇÃO}

A hérnia lombar ocorre em qualquer ponto da parede abdominal posterior, limitada superiormente pelos bordos inferiores das $12^{\text {as }}$ costelas, inferiormente pelas cristas ilíaca e medialmente pelos músculos eretores da espinha ${ }^{1}$. O primeiro caso de hérnia lombar foi descrito em 1731, por De Garengeot, que detectou hérnia lombar inferior em necrópsia ${ }^{2}$. Petit, em 1733, descreveu o ponto de saída da hérnia lombar inferior. Em 1866, Grynfeltt descreveu o espaço lombar superior, local mais freqüente das hérnias lombares ${ }^{3}$.

As hérnias lombares são incomuns, com menos de 300 casos descritos até o momento, e a ocorrência de encarceramento é rara ${ }^{1}$. O presente relato descreve um caso de abdome agudo obstrutivo e perfurativo por hérnia lombar encarcerada.

\section{RELATO DO CASO}

Paciente, masculino, 60 anos, obeso, apresentou dor abdominal difusa há 12 horas da internação, associada a parada de eliminação de gases e fezes e distensão abdominal. Há cinco anos havia notado abaulamento na região lombar esquerda, redutível e pouco doloroso. Há três meses a tumoração havia se tornado irredutível, surgindo crises recorrentes de dor abdominal difusa, espasmódica, com remissão espontânea. $\mathrm{O}$ exame físico na admissão revelava grande distensão abdominal, timpanismo difuso e dor à palpação difusamente, sem sinais de irritação peritoneal. Identificava-se abaulamento na região lombar esquerda, medindo $15 \times 15 \mathrm{~cm}$, consistência amolecida e irredutível. O paciente referia cirurgia prévia para correção de hérnia inguinal direita há 20 anos e negava episódio prévio de trauma abdominal.

Foi realizada tomografia computadorizada de abdome com contraste oral e venoso, que evidenciou pneumoperitônio e solução de continuidade na parede abdominal, em flanco esquerdo, correspondendo ao triângulo lombar superior, contendo cólon descendente, sem contraste no seu interior (Figuras 1 e 2).

Com a hipótese diagnóstica de abdome agudo obstrutivo e perfurativo, o paciente foi levado à laparotomia, onde identificou-se perfuração na parede anterior do ceco, de aproximadamente $1 \mathrm{~cm}$, e hérnia lombar à esquerda, com encarceramento do cólon descendente, sem sinais de estrangulamento. O intestino foi então reduzido e o orifício herniário reparado com fio inabsorvível. Optou-se por rafia

1. Médica residente de Cirurgia do Hospital Universitário da UnB

2. Professor-doutor titular de Cirurgia da Faculdade de Medicina da UnB

3. Professor adjunto de Cirurgia do Hospital Universitário da UnB

Recebido em 10/04/2002

Aceito para publicação em: 11/02/2003

Trabalho realizado no Serviço de Cirurgia Geral do Hospital Universitário da Universidade de Brasília (UnB). 


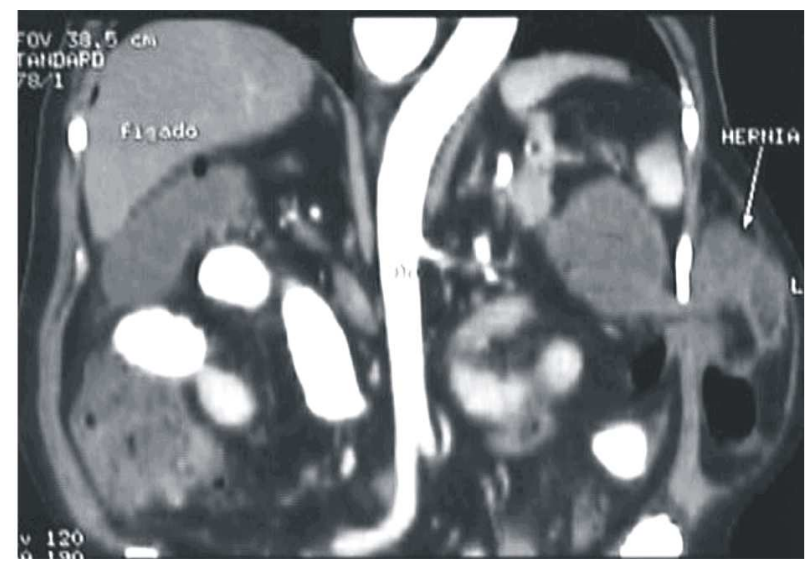

Figura 1 - Tomografia computadorizada de abdome demonstrando hérnia lombar esquerda.

primária do ceco devido à estabilidade clínica do paciente, presença de leve contaminação da cavidade sem peritonite e boas condições locais do segmento intestinal. $\mathrm{O}$ paciente evoluiu sem intercorrências, obtendo alta no $7^{\circ}$ dia de pós-operatório.

\section{DISCUSSÃO}

As hérnias lombares podem ocorrem em dois pontos de fraqueza da região lombar, o trígono lombar superior (triângulo de Grynfelt-Lesshaft) e inferior (triângulo de Petit). O primeiro é o mais freqüente e apresenta a forma de um triângulo invertido, limitado superiormente pela $12^{\text {a }}$ costela e borda inferior do músculo serrátil, anteriormente pela borda posterior do músculo oblíquo interno e posteriormente pelos músculos paravertebrais e quadrado lombar. $\mathrm{O}$ triângulo de Petit, está limitado inferiormente pela crista ilíaca, anteriormente pelo músculo oblíquo externo e posteriormente pela borda anterior do músculo grande dorsal ${ }^{4}$.

As hérnias lombares podem ser congênitas ou adquiridas. As hérnias congênitas são raras (20\%) e estão relacionadas a anóxia fetal e malformações. A maioria das hérnias adquiridas são espontâneas, correspondendo a $50 \%$ dos casos, e as demais são traumáticas (30\%). As hérnias adquiridas acometem

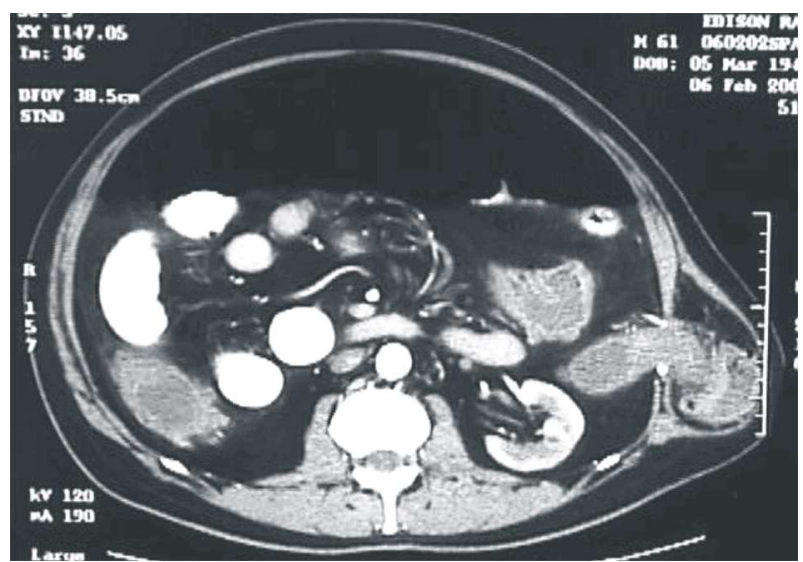

Figura 2 - Tomografia computadorizada de abdome pneumoperitônio e herniação do cólon sigmóide através do trígono lombar superior esquerdo.

predominantemente o sexo masculino, na proporção de $3: 1$, sendo mais comuns à esquerda $(2: 1)$ e no triângulo superior (hérnia de Grynfeltt) ${ }^{2}$, tal como o caso relatado. Os sintomas são inespecíficos ou inexistentes, podendo-se palpar tumor em região lombar, ao exame físico.

O diagnóstico pode ser determinado com bases clínicas. Entretanto, a utilização de métodos de imagem pode ser fundamental no diagnóstico diferencial. A ultra-sonografia demonstra falha na parede abdominal na região lombar e confirma o diagnóstico na maioria dos $\operatorname{casos}^{4}$. Recentes publicações descrevem a importância da tomografia computadorizada na identificação das hérnias lombares, com demonstração detalhada da anatomia ${ }^{5}$.

Quando não tratadas, as hérnias lombares podem atingir proporções gigantescas, aumentando os riscos de complicações graves. O encarceramento $(25 \%)$ e estrangulamento (10\%) não são freqüentes.

O tratamento é sempre cirúrgico, com o objetivo de reduzir a hérnia e reconstruir o defeito muscular da parede abdominal. Este resultado pode ser alcançado através da aproximação dos componentes musculares ou com a utilização de materiais sintéticos como as telas de marlex ${ }^{3}$. Várias técnicas podem ser utilizadas, sendo que o acesso videolaparoscópico possibilita reparo do orifício herniário com menor morbidade pós-operatória. 


\begin{abstract}
Lumbar hernia is defined as an abdominal passage through the posterior abdominal wall. Approximately 250 to 300 cases have been described in the literature, being quite infrequent. Untreated lumbar hernia may result in severe complications. The authors report a case of a 60 year old male patient presenting a large bowel obstruction and perfuration secundary to incarceration of descending colon within a lumbar hernia. This was diagnosed by clinical history and computed tomography. The patient was successfully treated surgically.
\end{abstract}

Key words: Hernia; Intestinal obstruction.

\section{REFERÊNCIAS}

1. Nyhus LM, Bombeck CT, Klein MS. - Hérnias. In Sabiston DC - Tratado de Cirurgia. $14^{\text {a }}$ Edição. Rio de Janeiro. Guanabara Koogan, 1991, pp. 1074-1088.

2. Thorek M. - Lumbar hernia. J Int Coll Surg, 1950, 14: 367-391.

3. Safatle NF, Almeida MCR, Ciasca Jr DV. - Hérnia de Grynfeltt-Lesshaft. Rev Col Bras Cir, 1986, 13(1): 1517.

4. Alves Jr A, Maximiano L, Fujimura I, et al. - Hérnia de Grynfelt: relato de caso e revisão da literatura. Rev Hosp Clin Fac Med Univ São Paulo, 1995, 50(2): 111114.
5. Baker ME, Weinerth JL, Andriani RT, et al. - Lumbar hernia: diagnosis by CT. AJR Am J Roentgenol, 1987, 148(3): 565-567.

Endereço para correspondência:

Dra. Sinthia Maria Benigno Puttini

SGAN 604

Hospital Universitário de Brasília

Anexo III - Residência Médica - quarto 10

70840-040 - Brasília - DF

E-mail: puttinismb@uol.com.br 